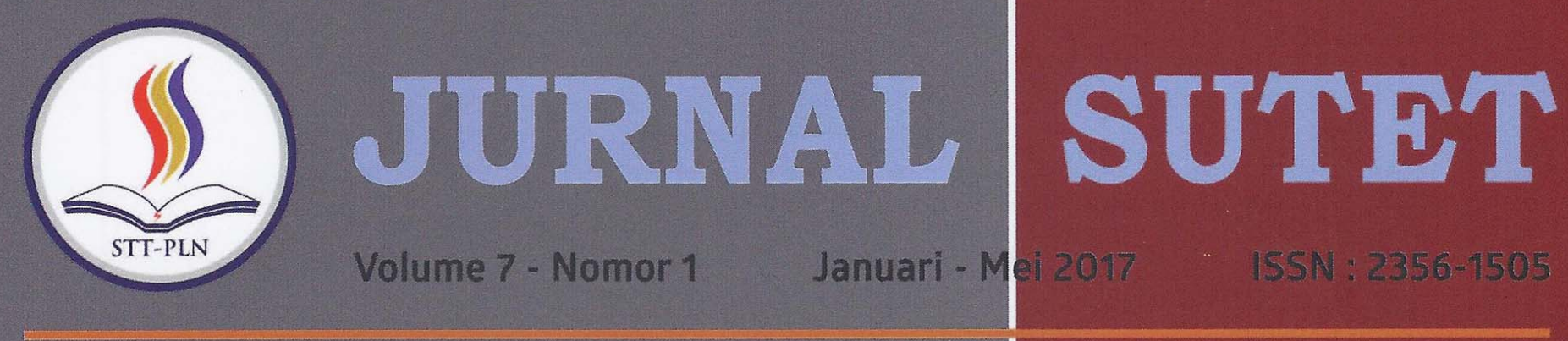

DESAIN SISTEM ALARM MOBIL BERBASIS SMS

Erlina; Hendrianto Husada; Bambang Tri Atmodjo

KELAYAKAN PENGGUNAAN PENDINGIN THERMOELEKTRIK UNTUK PENGHEMATAN DAYA LISTRIK PADA BASE TRANSCEIVER

Sunaryo; Uno Bintang Sudibyo; Supriadi Legino

WITRICITY (WIRELESS ELECTRICITY)

Aas Wasri Hasanah; Oktaria Handayani

CONCEPTUAL DESIGN FOR MITIGATING HARMONIC DISTORTION ON ESP INSTALLATION: CASE STUDY IN KAJI SEMOGA FIELD, MEDCO E\&P INDONESIA

Sandy Suryakusuma; Suprapto Atmowiranto; Dadang Darmawan

RANCANGAN RANGKAIAN ANTI BOUNCING UNTUK RANGKAIAN DIGITAL

Tasdik Darmana

STUDI POWER WHEELING DIKAWASAN INDUSTRI JABABEKA

Bimo Brillianta; Uno Bintang Sudibyo; Wildan Aripin

PEMASANGAN ARRESTER DAN ARCING HORN PADA PENGHANTAR BERISOLASI DI SUTM $20 \mathrm{kV}$ Christine Widyastuti; Andi Makkulau

PENGELOLAAN EMISI GAS LANDFILL (BIOGAS) SEBAGAI ENERGI TERBARUKAN Isworo Pujotomo; Muchamad Nur Qosim

DISAIN SISTEM PENTANAHAN PROTEKSI PETIR SISTEM MULTIPLE VERTICAL ELECTRODES PADA TERMINAL LAWE-LAWE - PERTAMINA DHP

Ibnu Hajar

ANALISA DCS (DISTRIBUTED CONTROL SYSTEM) PADA PROSES POLIMERISASI

Syarif Hidayat; Irsyadi Akbar Jay

PENGEMBANGAN TEKNOLOGI SISTEM SMART MICROGRID DI SEKOLAH TINGGI TEKNIK PLN Heri Suyanto; Agung Hariyanto

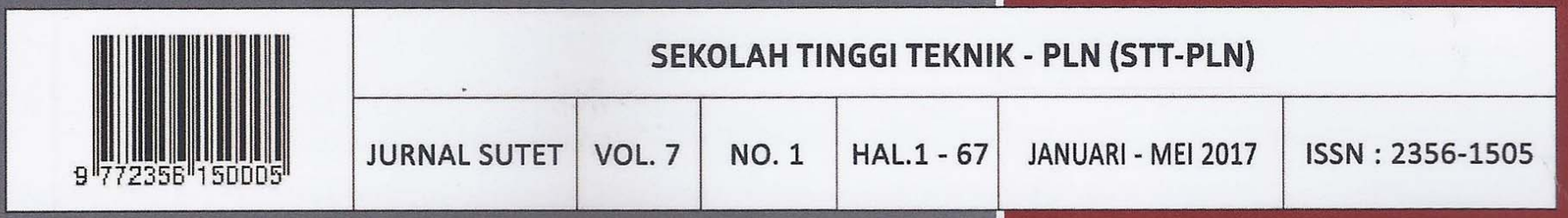




\title{
WITRICITY (WIRELESS ELECTRICITY)
}

\author{
Aas Wasri Hasanah ${ }^{1)}$, Oktaria Handayani \\ Teknik Elektro Sekolah Tinggi Teknik PLN - Jakarta \\ 1aas@sttpln.ac.id \\ ²octa.handa@gmail.com
}

\begin{abstract}
Electricity is an integral part of every human being and power transmission by wires is a necessityto fulfill the need of electricity. 'What if we can come out of this tangled wire-theory?'- With this view, Nikola Tesla introduced the concept of wireless power transfer in early 20th century. Wireless Power Transfer (WPT) is not only reliable and efficient but it is also eco-friendly and cost effective. A lot of concepts for WPT are already discussed by researchers, scientists and inventors. In addition to the available works and principles, this paper explains the basic concept, design and implementation of wireless electricity with magnetic induction technique and determining its practical result carried out with the same.
\end{abstract}

Keywords: Wireless power transmission, magnetic induction, electrical power, WPT.

Abstrak : Listrik merupakan bagian yang tidak terpisahkan bagi manusia dan transmisi energi listrik dengan menggunakan kabel adalah suatu keharusan untuk memenuhi kebutuhan listrik. "Bagaimana jika kita bisa keluar dari teori kabel yang membelenggu ini?". Dengan pandangan ini, Nikola Tesla memperkenalkan konsep Wireless Power Transfer pada awal abad 20. Wireless Power Transfer (WPT) tidak hanya handal dan efisien tetapi juga ramah lingkungan dan hemat biaya.Banyak konsep untuk WPT sudah dibahas oleh para peneliti, ilmuwan dan penemu. Selain karya-karya yang tersedia dan prinsip-prinsip, tulisan ini menjelaskan konsep dasar, desain dan implementasi Wireless Electricity (Witricity) dengan teknik induksi magnetik dan menentukan hasil praktisnya dilakukan dengan cara sama.

Kata Kunci: wireless power transmission, induksi magnet, daya listrik, WPT.

\section{PENDAHULUAN}

Listrik telah menjadi bagian yang tidak terpisahkan dari kehidupan kita. Listrik adalah sumber daya energi yang paling penting. Kita menggunakan listrik sebagai sumber energi di rumah-rumah, pabrik, kantor, sekolah dan lain-lain.

Namun umumnya, setiap kali kita berpikir tentang listrik, kita berpikir tentang kabel yang membawa arus listrik. Sistem listrik dengan kabel ditunjukkan pada Gambar 1.

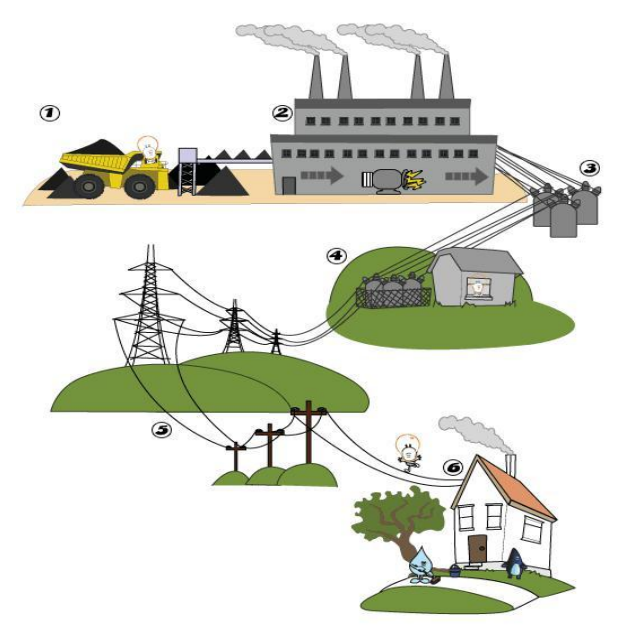

Gambar 1. Sistem listrik dengan kabel

Nicola Tesla dengan eksperimennya tentang kumparan tembaga (copper coil), memperkenalkan tentang Witricity. Witricity(wireless power transmission) 
adalah transmisi energi listrik tanpa kabel tanpa menggunakan media fisik. Awal abad 20 ia mulai bereksperimen dengan Radio Frequency Resonant Transformers yang menghasilkan Arus Bolak-balik (Alternate Current). Pada awalnya, ia mampu mengirimkan daya untuk jarak pendek dan sampai pada kesimpulan bahwa ia dapat meningkatkan jarak tersebut dengan menggunakan kopling induktif dan kapasitif. Tetapi eksperimen tersebut gagal karena adanya "near-field effect" dan difusi dari wireless power. Tesla mengembangankan sistem distribusi listrik massal tanpa kabel yang bisa mengirimkan daya ke pabrik dan rumah secara langsung. la mulai membangun fasilitas kumparan bertegangan tinggi, yaitu Menara Wardenclyffe di Shoreham, New York dan diusulkan sebagai pola dasar pemancar untuk "World Wireless System" yang dapat mengirimkan listrik ke seluruh dunia, tetapi pada tahun 1904 Tesla kehabisan dana penelitian dan fasilitas ini tidak pernah selesai, sebuah mahakarya dengan biaya besar telah dihabiskan dari distribusi daya tanpa kabel tidak dapat dikembangkan

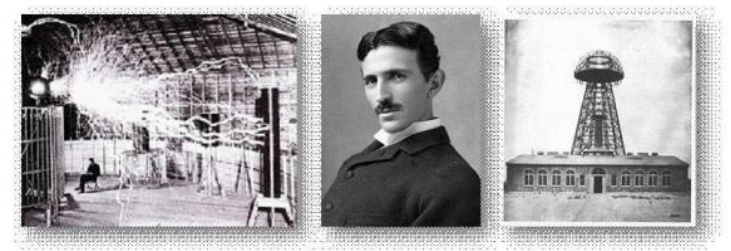

Gambar 2.Nikola Tesla, percobaanya, dan Menara Wardenclyffe

Mimpi Tesla yang sangat menarik tersebut dilanjutkan oleh tim peneliti dari Massachusetts Institute of Technology (MIT) dipimpin oleh Mr Marin Soljacic.

Pada tahun 2007 tim peniliti MIT melanjutkan mimpi Tesla, yaitu dengan merangkai resonan berupa gulungan kawat tembaga yang disesuaikan dengan kapasitansi internal pada $10 \mathrm{MHz}$. Daya digabungkan ke resonator pemancar dan keluar dari resonator penerima ke penyearah dengan gulungan kecil yang berfungsi untuk pencocokan impedansi.

Witricity didasarkan pada benda resonansi elektromagnetik yang digabungkan untuk mentransfer energi tanpa kabel. Sistem ini terdiri dari pemancar dan penerima yang memiliki magnet loop antena dengan frekuensi yang sama.

Mereka mengusulkan istilah "Witricity" untuk pertama kalinya dengan menggunakan konsep dari Tesla dalam percobaan dan menyalakan sebuah lampu 60W tanpa menggunakan kabel pada jarak 7 kaki (2,134 meter) dengan efisiensi $40 \%$.

\section{KAJIAN LITERATUR}

Istilah Witricity didefinisikan sebagai kemampuan untuk memasok energi listrik untuk peralatan yang jauh dengan menggunakan medan magnet yang berosilasi.

Penelitian ini dimulai oleh Prof. Soljacic dengan ide pengisian ponsel tanpa menggunakan kabel.

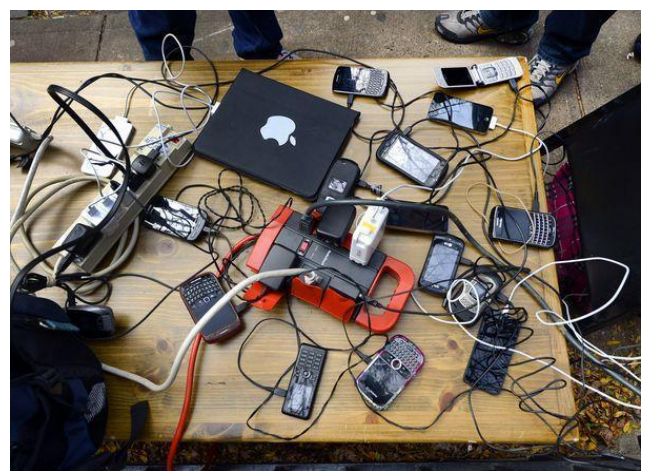

Gambar 3. Mengisi baterai dengan menggunakan kabel

Konsep dasar, dua benda yang memiliki sistem resonansi magnetik dan beresonansi frekuensi yang sama, apabila dipasangkan akan bertukar energi dan energi yang terbuang lebih sedikit dibanding benda yang tidak beresonansi dan tidak terhubung.

\subsection{Radiasi Elektromagnetik}

Dalam metode ini, energi radiasi dilepaskan oleh beberapa proses elektromagnetik dan daya yang ditransmisikan dipancarkan ke segala arah. Jadi jumlah daya yang dibutuhkan tidak dapat diterima oleh receiver atau penerima. Radiasi tersebut dapat dimanfaatkan untuk mengirimkan informasi pada jangkauan jarak jauh. 


\subsection{Teknik Optik}

Dalam metode ini, energi ditransmisikan dalam bentuk cahaya sebagai wireless power transmission (WPT) dengan menggunakan laser. Laser memiliki gelombang elektromagnetik yang terarah dan energi yang dihasilkan dapat ditransmisikan menuju area yang luas. Metode ini berhasil hanya untuk penerima statis.

\subsection{Gelombang Mikro}

Teknik ini sama dengan radiasi di alam. Energi ini dapat ditransmisikan menggunakan frekuensi gelombang mikro sebagai wireless power transmission [11]. Jarak jangkauan untuk metode ini tinggi tetapi sama sekali tidak ramah lingkungan/ aman bagi manusia karena frekuensi gelombang mikro pada tingkat daya yang lebih tinggi dapat membahayakan manusia.

\subsection{Induksi Elektrodinamika}

Metode induksi elektrodinamika benar-benar ramah lingkungan, tidak terdapat radiasi dan metode yang aman dari wireless power transmission. Dalam metode ini, dua objek yang beresonansi pada frekuensi yang sama bertukar energi. Kemungkinan dapat digunakan pada jarak yang lebih jauh karena memiliki banyak penempatan pemancar (transmitter) dan penerima (receiver). Tim peneliti dari MIT menggunakan metode yang sama untuk menciptakan istilah Witricity pada tahun 2007.

\subsection{Induksi Magnetik}

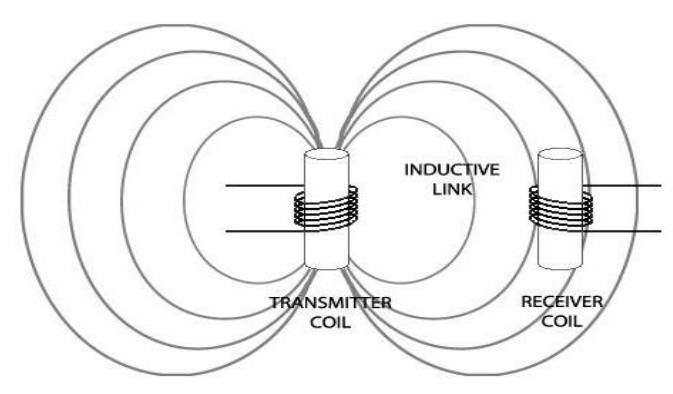

Gambar 4. Induksi Magnetik

Teknik ini memiliki biaya yang efektif dan metode yang dapat diandalkan dari wireless power transmition yang tidak mengakibatkan radiasi di alam. Metode ini mengikuti hukum induksi bersama. Dalam metode ini, sebuah kumparan membawa arus yang menghasilkan medan magnet. Pada kumparan konduksi kedua, ketika didekatkan dengan kumparan pertama, kumparan tersebut menangkap beberapa bagian dari medan magnet yang berosilasi, yang kemudian menginduksi arus listrik di kumparan kedua. Arus yang dihasilkan dalam kumparan induktif kedua dapat digunakan untuk memasok energi untuk perangkat yang berbeda.

\section{METODE PENELITIAN}

Konsep dasar pendekatan elektromagnetik WPT adalah induksi magnetik antara dua kumparan yaitu kumparan transmitter (pemancar) dan kumparan receiver (penerima). Ketika kumparan transmitter menyalurkan tenaga yang kemudian menghasilkan energi maka kumparan receiver akan menerima energi tersebut, perbedaan potensial dihasilkan di terminal ini. Beda potensial yang dihasilkan di dalam receivers, secara langsung berkaitan dengan jarak antara kumparan receiver dan kumparan transmitter. Prinsip dasar dari suatu sistem transfer energi listrik dengan induksi bersama ditunjukkan pada Gambar 5. Pada gambar tersebut dapat dilihat bahwa terdapat kumparan transmitter $\mathrm{L} 1$ dan kumparan receiver $\mathrm{L} 2$. Kedua kumparan tersebut membentuk sistem induksi magnet bersama. Arus bolak-balik (AC) dalam kumparan transmitter menghasilkan medan magnet yang menginduksi tegangan di kumparan receiver. Tegangan tersebut kemudian dapat digunakan untuk mengisi daya perangkat mobile atau mengisi baterai.

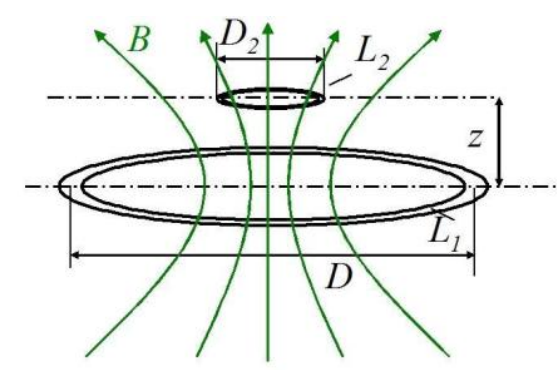

Gambar 5. Sususan khusus dari sebuah sistem transfer energi listrik secara induksi bersama 
Sedangkan diagram penggunaan induksi magnetik ditunjukkan pada gambar di bawah ini:

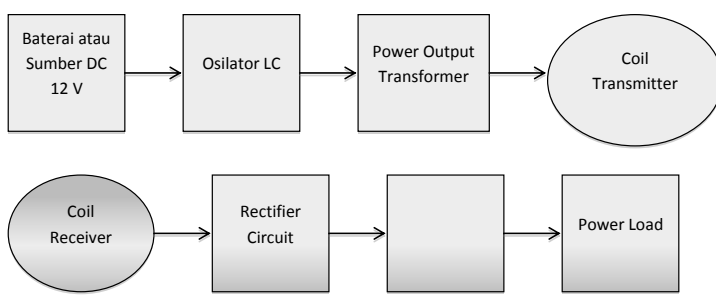

Gambar 6. Diagram Blok dari WPT menggunakan Induksi Magnetik

Sistem ini terdiri dari dua bagian, yaitu bagian transmitter dan bagian receiver.

Dimana kumparan pemancar mengubah daya $D C$ untuk sinyal $A C$ frekuensi tinggi dan kumparan receiver menerima energi listrik dan mengubahnya menjadi sinyal DC.

Pada bagian transmitter:

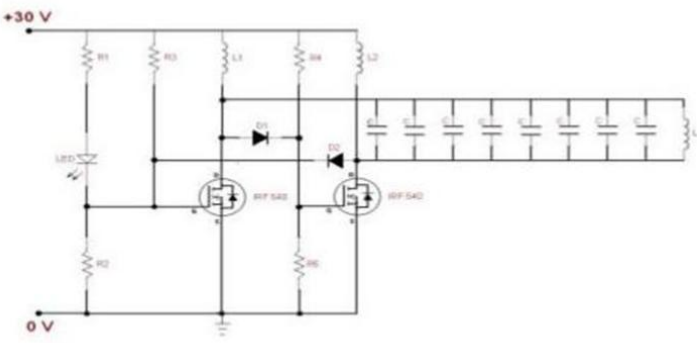

Gambar 7. Rangkaian Transmitter

Sumber DC memiliki transformator step down yang menurunkan suplai tegangan, dan rangkaian penyearah mengkonversikan tegangan $\mathrm{AC}$ ke sinyal DC. Rangkaian Oscillator dapat dengan mudah mencapai arus yang berosilasi tinggi untuk kumparan transmitter. Dua channel $\mathrm{N}$ meningkatkan MOSFET yang digunakan. Ini juga memiliki sebuah kumparan transmitter $\mathrm{L}$ (induktor) dan beberapa resistor R1, R2, R3 dan R4.

Frekuensi operasi dari oscillator ditentukan oleh rumus resonansi berikut,

$$
f=\frac{1}{2} \pi \sqrt{L C}
$$

Bagian Receiver.

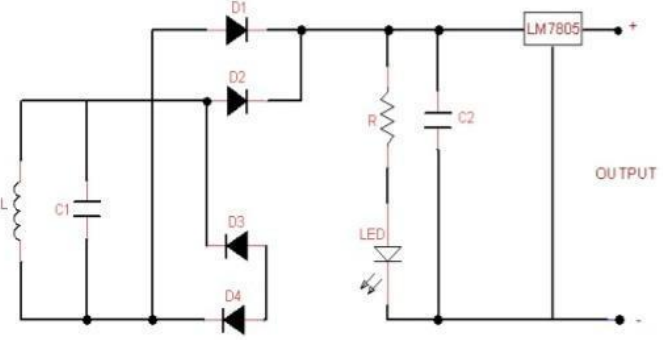

Gambar 8. Bagian Receiver

Pada bagian ini terdiri dari sebuah kumparan receiver, rangkaian penyearah dan IC regulator tegangan. Rangkaian penyearah di bagian receiver mengkonversi tegangan AC menjadi DC. IC pengontrol tegangan membantu untuk menyediakan tegangan output yang diatur tetap konstan pada beban untuk pengisian. IC regulator tegangan yang digunakan adalah LM 7805. IC diatur pada tegangan $5 \mathrm{~V}$ sebagai outputnya.

Impedansi kumparan transmisi dibuat dengan 250 putaran dengan diameter 6 inci. Induktansi yang dihasilkan memberikan output maksimum.

\section{HASIL DAN PEMBAHASAN}

Kumparan menghasilkan tegangan AC sekitar 2,5 - 6 Volt, ini tergantung pada jarak antara dua kumparan. Output dari kumparan kedua yang disearahkan dan terhubung dengan rechargeable battery adalah 4,5 - 5 Volt. Dengan menggunakan output inverter dihasilkan tegangan $6 \mathrm{~V} 20$ Watt

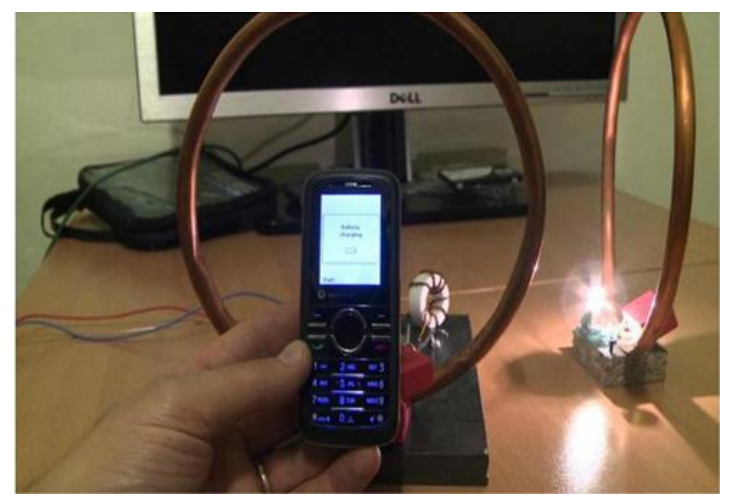

Gambar 9. Pengisian HP menggunakan teknik induksi magnetik 


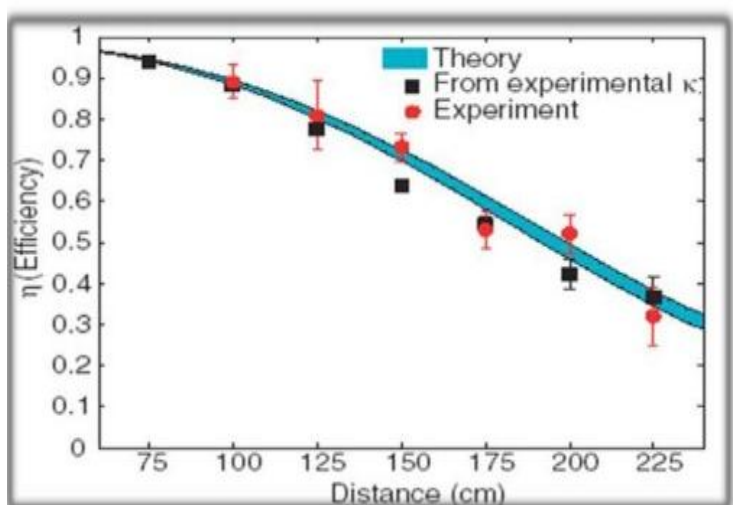

Gambar 10. Grafik Effesiensi witricity

\section{Keuntungan dari Witricity}

1. Integritas transmisi tinggi dan rugi-rugi daya rendah

2. Biaya perawatan yang rendah

3. Ramah lingkungan

4. Kebutuhan untuk baterai dihilangkan

5. Tidak terpengaruh oleh cuaca, waktu dan musim

6. Penggunaan yang efektif untuk perangkat yang mengkonsumsi daya dengan rentang sedang

\section{KESIMPULAN}

Transmisi energi listrik tanpa kabel bukan lagi teori, namun sekarang telah menjadi kenyataan. Energi listrik dapat secara ekonomis ditransmisikan tanpa menggunakan kabel. Banyak peneliti telah bekerja dan mengembangkannya pada banyak pengamatan, percobaan dan pengukuran, kualitatif dan kuantitatif. Nikola Tesla adalah orang yang berjasa dalam penemuan ini. Transmisi energi listrik tanpa kabel memiliki kelebihan yang luar biasa seperti integritas transmisi yang tinggi dan rugi-rugi rendah $(90-97 \%$ efisien) dan dapat disalurkan ke mana saja di dunia dan menghilangkan kebutuhan yang tidak efisien seperti berbayar, modal jaringan kabel yang intensif, menara, dan gardu. Sistem ini akan mengurangi biaya energi listrik yang digunakan oleh konsumen dan menyingkirkan lanskap kabel, kabel, dan menara transmisi. Sistem ini memiliki kekurangan yang dapat diabaikan seperti daya reaktif yang ditemukan tidak signifikan dan kecocokan biologis. Selain itu juga memiliki dampak ekonomi yang besar kepada masyarakat umum. Banyak negara akan mendapatkan keuntungan dari layanan ini.

Untuk selanjutnya dapat dikembangkannya sistem transmisi energi listrik dengan ukuran yang lebih kecil, dengan efisiensi yang lebih baik dengan jarak yang jauh. Efisien sistem transmisi energi listrik tanpa kabel dapat dirancang di masa depan untuk mengirimkan puluhan ribu KW daya melewati ratusan mil dengan efisiensi dan kinerja yang maksimum.

\section{REFERENSI}

[1]. Connie Jenkins, 2014, Nikola Tesla 192 Success Facts - Everything you need to know about NikolaTesla. Emereo Publishing.

[2]. Franklin Hadley, 2007: Good Bye Wires, Institute for Soldier Nanotechnologies, MIT

[3]. James J. Jong Hyuk Park, Yi Pan, Cheon-Shik Kim, Yun Yang, 2014, Future Information Technology Springer Science \& Business.

[4]. Johnson I. Agbinya, 2012 : Wireless Power Transfer, River Publishers.

[5]. Kevin Roebuck, 2012, Wireless Power: High-impact Emerging Technology, Emereo Publishing, ISBN 1743045433, 9781743045435

[6]. Mark S. Humayun, James D. Weiland, Gerald Chader, Elias Greenbaum, 2007 : Artificial Sight: BasicResearch, Biomedical Engineering, and Clinical Advances, Springer Science \& Business Media.

[7]. Nikola Tesla, David Hatcher Childress, 1993, The Fantastic Inventions of Nikola Tesla, Adventures Unlimited Press.

[8]. Nikola Tesla, January 7, 1905, Article: The Transmission of Electrical Energy without Wires as a Means for FurtheringPeace.

[9]. Rajen Biswa, may 2012 : Feasibility of wireless power transmission,

[10].Stephen F. Bush, 2014,Smart Grid: Communication-Enabled Intelligence for the Electric Power Grid : John Wiley \& Sons.

[11].Zhijing Liu, 2015, Control Engineering and Information Systems : CRC Press. 